Nig. J. Biotech. Vol. 33 (2017) 120-124

ISSN: 01891731

Available online at

http://www.ajol.info/index.php/njb/index

and www.biotechsocietynigeria.org

DOI: https://dx.doi.org/10.4314/v33i1.17

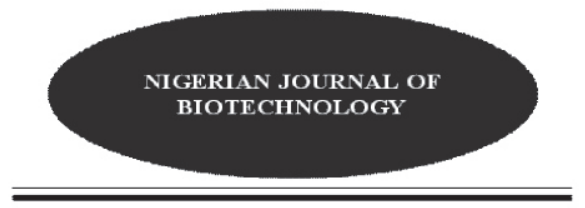

\title{
Evaluation of two MiniSTR loci mutation events in five Father-Mother-Child trios of Yoruba origin
}

\author{
Awe, E. T., Akpan, U. U. and Adekoya, K. O. \\ Department of Cell Biology and Genetics, University of Lagos, Nigeria.
}

(Received: 21:06:2017; Accepted:14 :08:2017)

\author{
Copyright resides with the authors in terms of the Creative Commons License 4.0. \\ See http://creativecommons.org/licenses/by/4.0/ \\ Condition of use: The user may copy, distribute, transmit and adapt the work, but must recognize the \\ authors and the Nigerian Journal of Biotechnology
}

\begin{abstract}
The robustness of short tandem repeats for use in forensic and paternity depends on their high polymorphism and mutation rate. This study tried to determine the event of mutation of two miniSTR loci in the Yoruba population. Blood samples were collected from five father-motherchild trios of Yoruba origin. Two DNA extraction methods, an homemade method and Zymogen gDNA kit were tested for yield and purity for use in the STR assay. The DNA were amplified and resolved on 4\% Agarose gel. The first DNA extraction method yielded an average DNA concentration of $1399 \mathrm{ng} / \mu \mathrm{l}$ and while the Kit yielded $984.1 \mathrm{ng} / \mu \mathrm{l}$; absorbence quotient at 260/280 of 1.78 and 1.55 respectively. Locus D1GATA113 was detected in the father and mother of two families; A and C. D5S2500 was detected only in the male parent (father) in family D. DNA extracted using any of the two methods in this study is appriopriate for use in STR mutation assay but the PCR condition for mutation miniSTR loci among the yoruba still requires extensive optimization.
\end{abstract}

Keywords: DNA extraction Methods, miniSTRs, mutation, Yoruba

Correspondence: topeawela@gmail.com

\section{Introduction}

Genetic identity testing involves identifying patterns of genetic material that are unique to almost every individual. Short tandem repeats (STRs), which according to Schoske et al., (2003) are repeating DNA sequences which are approximately 2-6 base pairs in length; are the most commonly used loci for human identification simply because of their high polymorphism, requirement of minimal template DNA and possession of a narrow size range that makes multiplexing easy (Butler, 2005; Opel et al., 2006).

Most STRs are found in the noncoding regions, while only about $8 \%$ locate in the coding regions (Ellengren, 2000). About $90 \%$ of STR existing in non-coding regions of the genome have prompted the question of what could be the function of these frequently repeating sequences. Over the last decades, several potential functions of some STR in the regulation of transcription of genes like the epidermal growth factor gene (Gebhardt, et al 1999), P-53 Inducible Gene-3 (Contente et al., 2002) and the regulation of gene expression (Heale and Pete, 1995), have been reported. The mutation rates in STR sequences are several orders of magnitude higher ranging from $10^{-6}-10^{-2}$ nucleotides per generation in human (Fan and Chu, 2007), than in 'regular' DNA sequences in the genome (Ellengren, 2000). The chances of detecting germline genomic mutations have also increased with the use of STR markers due to their higher mutation rate when compared to other genetic markers. STR systems are nowadays the most commonly used systems in human identity and paternity cases.

MiniSTRs are now been widely employed due to the limitations of STRs to produce full genetic profiles in degraded DNA samples in forensic and paternity case. MiniSTRs improve the chance of obtaining STR results 
from samples with compromised DNA. This involves the redesigning of the primer binding sites of some STR loci to produce shorter amplicons (Gill et al., 2006). The miniSTR primer sets produce full genetic profiles in the majority of the samples containing degraded DNA (Butler, 2005); and have the potential to provide additional discrimination in complex paternity cases or missing persons cases (Goodwin et al., 2004).

There has been no data on miniSTR analysis on Nigerian populations most especially the Yorubas. This study tends to fill literature gap and provide foundational data on miniSTR analysis in Yoruba population of Nigeria, by evaluating the presence of two miniSTR loci and the event of mutation on the Yoruba population.

\section{Materials and Method}

The study was part of a larger study on the proficiency of STR in the Nigerian population for which ethical clearance with reference ADM/DCST/HREC/1921 was obtained from the institutional Review Board of the Lagos University Teaching Hospital (LUTH) Nigeria.

The individuals who participated in this study were duly educated on the research, and they signed informed consent documents. Five (5) families from Ilesha, Osun state $(A, B, C, D, E)$, volunteered to participate in the research and met all the inclusion criteria in the study. Two mls of blood were obtained from each participants. The blood samples were transported in an ice flask to the Genetics Laboratory of the Department of Cell Biology and Genetics University of Lagos, and stored at $-4^{\circ} \mathrm{C}$ until DNA extraction.

DNA were extracted from blood using two methods; a homemade method proposed by Iranpur and Esmailizadeh (2014) and Zymogen ${ }^{T M}$ gDNA extraction kit. Using the first method, 500 microlitres of each blood sample was pipetted into 1.5 $\mathrm{ml}$ eppendorf tube and then $1000 \mu \mathrm{l}$ of red cell lysis buffer was added. The tubes were spun for 2 minutes at $7000 \mathrm{rpm}$ and supernatants discarded The steps were repeated until all hemoglobins were removed. The tubes were allowed to drain after which $400 \mu$ l of nucleic lysis buffer was added to the eppendorf tubes and vortexed till all pellets were dissolved, followed by the addition of $100 \mathrm{ul}$ of saturated $\mathrm{NaCl}(5 \mathrm{M})$ and $600 \mu \mathrm{l}$ of chloroform and spun for 2 minutes at $7000 \mathrm{rpm} .400 \mu \mathrm{l}$ of supernatant was transferred to a new $1.5 \mathrm{ml}$ tube and $800 \mu \mathrm{l}$ of cold $\left(-20^{\circ} \mathrm{C}\right)$ absolute ethanol was added to precipitate DNA and vortexed. The tubes were spun for one minute at $12000 \mathrm{rpm}$, and then the supernatant discarded carefully. Fifty microlitres of TE buffer was added and then vortexed. The eppendorf tube with DNA was kept at $4^{\circ} \mathrm{C}$.

For the second method using Genomic DNA extraction kit $\left(\right.$ Zymogen $\left.^{\mathrm{TM}}\right)$, the extraction was done with 100ul of each blood sample following the manufacturer's instructions. The kit contained ZymoSpin IIC ${ }^{\mathrm{TM}}$ column, Genomic lysis buffer, pre DNA wash buffer, gDNA wash buffer and DNA elution buffer.

Spectrophotometric assay of DNA was performed to compare the density and concentration of DNA in the samples from the two methods of extraction using a Cary 60 UV-visible spectrophotometer (Agilent Technologies, Santa Clara, CA, USA). Absorbance was measured at wavelengths of 260 and $280\left(A_{260}\right.$ and $A_{280 \prime}$ respectively) $\mathrm{nm}$.

The integrity of genomic DNA of the two extraction methods were tested by resolving DNA extracts on a $1 \%$ agarose gel by electrophoresis (BioRad, Hercules, CA, USA) ran at 70 volts for 45 minutes.

MiniSTR primers used were obtained from list of 26 characterized miniSTR by Hill et al., (2008). The primers were procured from Eurofin Genomics $®$ (Table 1 )

The PCR was carried out using the Gene Amp® PCR

Table 1: MiniSTR Loci Primer Sequences.

Locus Name Primer Sequence

D1GATA113 F - TCTTAGCCTAGATAGATACTTGCTTCC

R- $\quad$ GTCAACCTITGAGGCTATAGGAA

D5S2500

F - CTGTTGGTACATAATAGGTAGGTAGGT

R - GTCGTGGGCCCCATAAATC

Hill et al. (2008) 
System 9700 (Appled Biosystems) in a total reaction of 20ul containing $5 x$ reaction master mix (Solis BioDyne), genomic DNA (2ul) and 2ul of each forward and reverse primer. The primers were run in singleplexes, using a pre-heating condition of $95^{\circ} \mathrm{C}$ for 10 mins, followed by 28 cycles of 45 secs denaturation at $94^{\circ} \mathrm{C}, 2$ minutes annealation for each of the two primers D1GATA113 and D5S2500 at $60.25^{\circ} \mathrm{C}$ and $60.35^{\circ} \mathrm{C}$ respectively.

The PCR products were resolved in $4 \%$ agarose gel at 70 volts for 45 minutes. Twenty base pair (20bp) DNA ladder was loaded as DNA size marker to monitor the bands sizes.

\section{Results}

The Iranpur and Esmailizadeh (2014) extraction method yielded an average DNA concentration of $1399 \mathrm{ng} / \mu \mathrm{l}$, while the Zymogen DNA Kit yielded $984.1 \mathrm{ng} / \mu \mathrm{l}$ yield (Table 3 ). The absorbance quotient at 260/280 of the Iranpur and Esmailizadeh (2014) is 1.787 ? while the kit produced an average of $1.547 ?$.

Table 2: DNA concentration summary in ng/ul.

\begin{tabular}{lllll}
\hline DNA Extraction methods & N & Sum & Average & Variance \\
\hline Iranpour and & & & & \\
Esmailizadeh (2014). & 15 & 20984 & 1399 & 209.0 \\
Zymogen DNA Kit & 15 & 14762 & 984.1 & 156.3 \\
\hline
\end{tabular}

Table 3: Summary of Absorbance quotients at $260 / 280$ in ?

\begin{tabular}{lcccc}
\hline Groups & $\mathrm{N}$ & Sum & Average & Variance \\
\hline $\begin{array}{l}\text { Iranpour and Esmailizadeh } \\
(2014)\end{array}$ & 15 & 26.800 & 1.787 & 0.09605 \\
Zymogen DNA Kit & 15 & 23.206 & 1.587 & 0.1536 \\
\hline
\end{tabular}

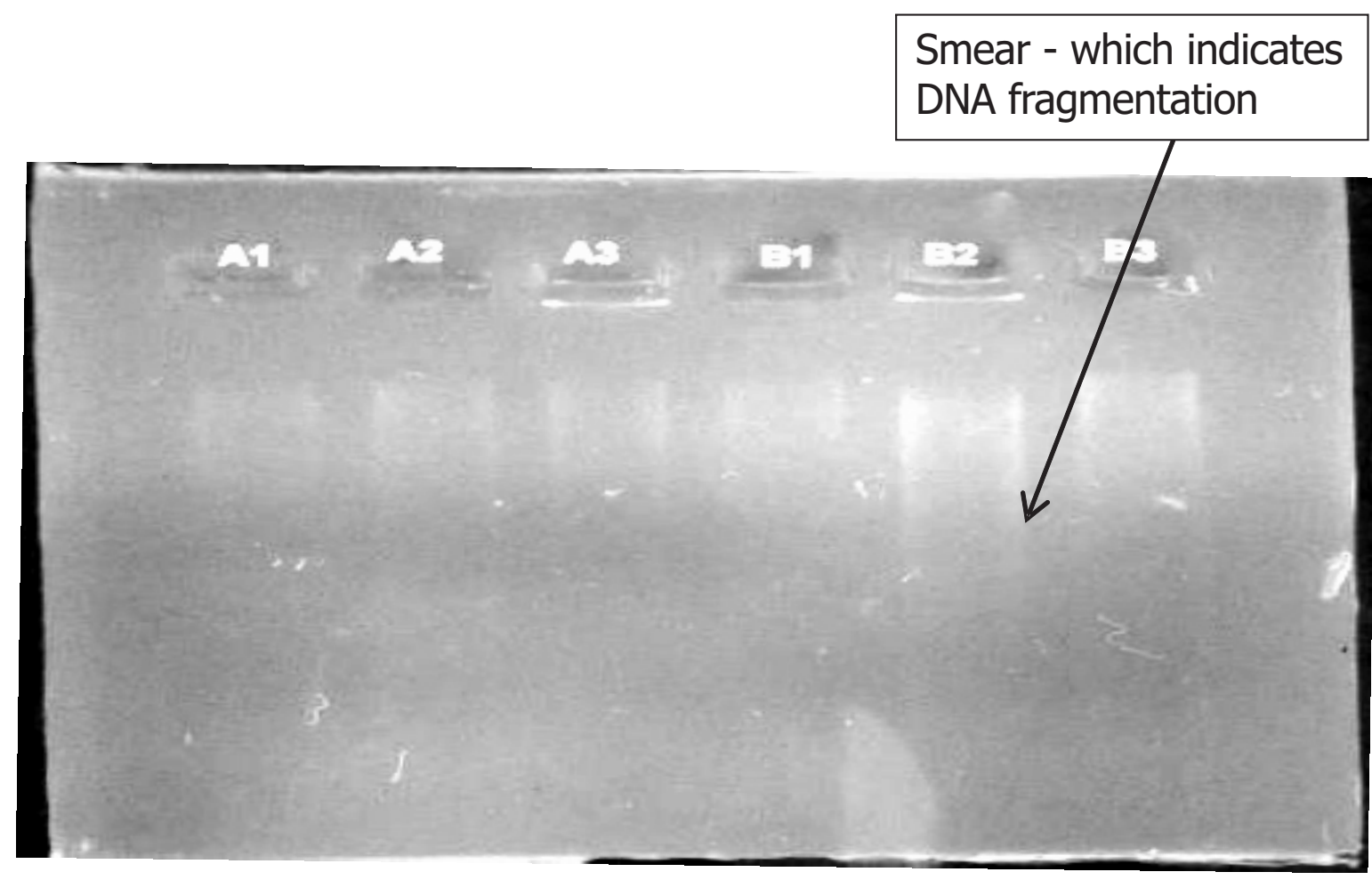

Fig 1: A Gel representing DNA concentration of samples extracted using Kit in agarose gel electrophoresis. 


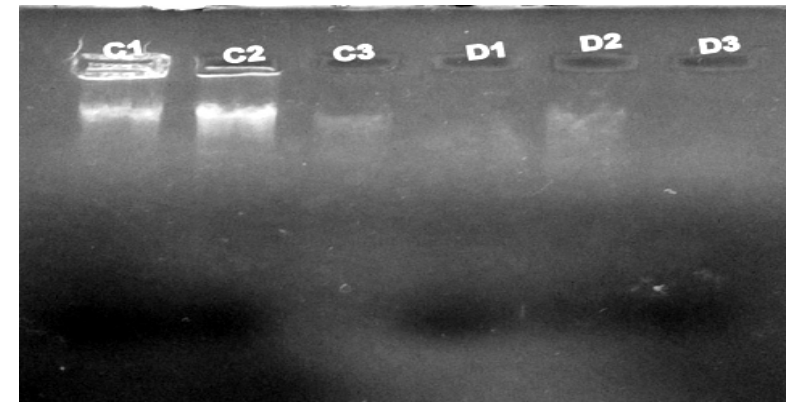

Fig 2: A Gel representing DNA concentration of samples extracted using the homemade method in agarose gel electrophoresis. The alphabets from the labellings represent the Family tags while the numbers represent members of the family father, mother, child respectively.

The result of the PCR amplification after running in 4\% agarose detected loci D1GATA113 (Fig 3) in two families though not up to a trio set in each family and loci D5S2500 was detected in one family (Fig 4).

The few amplicons produced also couldn't separate very well for us to see the alleles of the band and this improper separation is the same of the ladder marker that was used in the electrophoresis (fig 4).

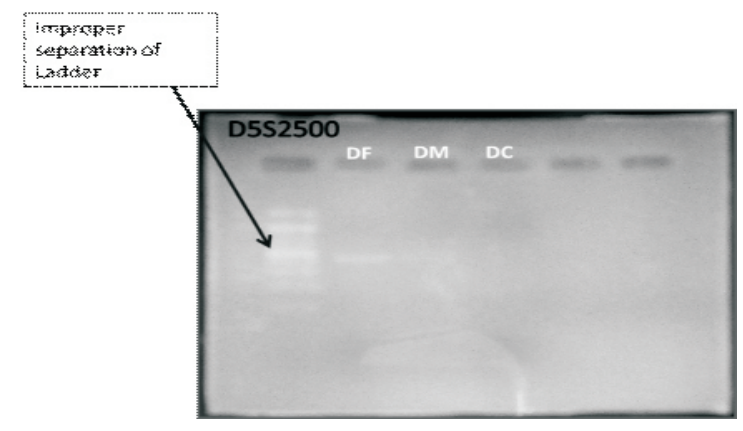

Fig 4: Amplification D5S2500 in family C. This ladder is showed the amplicon of primer D5S2500 on Family D-father alone and nothing on the mother (DM) and Child (DC) of the same family.

\section{Discussion}

DNA fingerprinting has been very helpful in forensic identification especially the use of miniSTR. However, the marker to use must first be validated for its polymorphism within the population. The DNA concentration average value of $1399 \mathrm{ng} / \mathrm{ml}$ and $984.1 \mathrm{ng} / \mathrm{ml}$ obtained from the two extraction methods for this study cannot be said to be too low for STR mutation analysis. Though, the amount of DNA obtained using the Iranpur and Esmailizadeh's (2014) method is higher than the yields from the extraction kit, which may be as a result of the difference in the amount of blood used to get a $50 \mathrm{ul}$ of dissolved DNA. The Iranpur and Esmailizadeh,

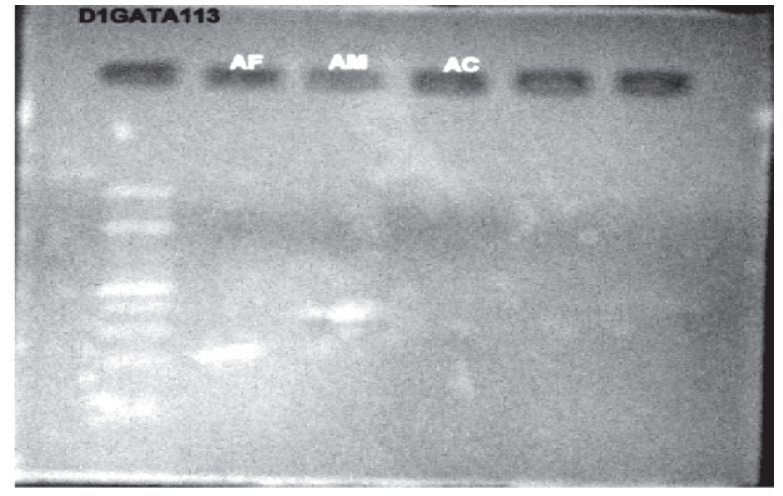

Fig 3: Amplification of D1GATA113 in family A. This figure showed amplicons on AF (Family A-father) and AM (Family A-mother) but nothing showed on Family $A$ child (AC).

method requires $500 \mathrm{ul}$ of blood, while the extraction kit used up $100 \mathrm{ul}$ of blood in each sample to give 5 ul of DNA in solution. STR was specifically designed because many samples recovered from crime scenes yield only few nanogram or picogram amounts of DNA that is sometimes degraded (Edwards, et al., 1992). Based on amount of DNA, both methods are still proficient for use in STR mutation assays. However, purity of DNA is of greater concern as contamination of samples (Lorenz, 2012) by RNA, protein(s), enzymes like nuclease(s) may yield poor amplification.

Absorbance quotient value ranging from 1.8 $2.0 ?$, is indicative of good and purified DNA (Ghatak et al. 2013). This implies that Iranpur and Esmailizadeh) extraction method yielded the purest DNA of the two methods. Though, on the overall, the amplicon frequency was low in both methods, which probably means the methods have nothing to do it the frequency of amplicons recorded. Another observation of interest that featured in our result is the presence of smear in samples extracted with the kit, which is an indication of fragmented DNA samples and when in comparison with Iranpur and Esmailizadeh method was inferior. But the fragmentation of DNA should not influence miniSTR mutation results which have reduced-size amplicons (Butler, 2005).

The allele sizes of the amplicons are compared between parents and off-springs to determine if mutation occurred. In this study, loci D1GATA113 could only be detected in two members of family $A$ and $C$, and loci D5S2500 detected only in the father of family $D$. The lack of amplification in all the families may be as a result of inappropriate PCR conditions like reagent concentrations, cycling conditions (Lorenz, 2012). Commonly implicated reagents whenever a standard PCR conditions did not yield the desired amplicons are the $\mathrm{Mg} 2+$, primer concentration or both. The contamination of DNA or reagents used could also result in low amplicon yield.

The PCR products, could not separate well in $4 \%$ 
agarose gel. The improper separation of the $20 \mathrm{bp}$ ladder used as rule marker confirmed this. This result contradicts White and Kuskawa, (1997) reports that agarose gel is sufficient for analysis of samples for several commonly used STR loci. This probably can also be because, the miniSTR are rather shorter compared to regular STR sizes. The relative 'ease' or 'difficulty of electrophoretic discrimination between different alleles is determined by the size of the repeating units (White and Kuskawa, 1997). Many research studies on STR in the recent years have been run on polyacrylamide gel (Hill, et al. 2008; Iranpur and Esmailizadeh, 2014). Since the alleles didn't come up probably because inappropriate PCR conditions and improper separation of the agarose gel used, the allele bands could not be scored.

This study reveals that DNA extracted using any of the two methods in this study is appriopriate for use in STR mutation assay. However, the PCR condition for detecting the type and frequency of mutations of miniSTR loci among the Yoruba population still requires extensive optimization. Most importantly, this is the first study to detect miniSTR loci in a Yoruba population.

\section{References}

Butler, J. (2005). Forensic DNA typing: biology, technology, and genetics of STR markers. London: Elsevier Academic Press, 489-92.

Contente, A., Dittmer, A., Koch, M., Roth, J., and Dobbelstein, M. (2002). A polymorphic microsatellite that mediates induction of PIG3 by p53. Nat. Genet., 30: 315-320.

Edwards, A., Hammond, H., Jin, L., Caskey, C., and Chakraborty, R. (1992). Genetic variation at five trimeric and tetrameric tandem repeat loci in four human population groups. Genomics 12: 241-253.

Ellengren, H. (2000). Heterogeneous mutation processes in human microsatellite DNA sequences. Nat. Genet. 24: 400-402.

Fan, H., and Chu, J. (2007). A brief review of short tandem repeat mutation. Genomics, Proteomics and Bioinformatics 5(1): 1-14

Gebhardt, F., Zanker, K., and Brandt, B. (1999). Modulation of epidermal growth factor receptor gene transcription by a polymorphic dinucleotide repeat in intron 1. J. Biol. Chem. 274: 1317613180.

Ghatak, S., Muthukumaran, R., and Nachimuthu, S. (2013). A simple method of genomic DNA extraction from Human samples for PCR-RFLP analysis. J. Biomol. Tech., 24:224-231

Gill, P., Fereday, L., Morling, N., and Schneider, P. (2006). The evolution of DNA databases recommendations for new European loci. Forensic Sci. Int. 156: 242-244.

Goodwin W, Ballard D, Simpson K, Thacker C, Syndercombe C. D., and Gow J. (2004). Case study: paternity testing - when 21 loci are not enough. In: Doutremepuich C, Morling N, editors. Progress in forensic genetics 10. Amsterdam, the Netherlands: International Congress Series, 1261: 460-2.

Heale, S.M. and Petes, T.D. (1995). The stabilization of repetitive tracts of DNA by variant repeats requires a functional DNA mismatch repair system. Cell 83: 539545.

Hill, C. R., Kline, M. C., Coble, M. D., and Butler, J. M. (2008). Characterization of 26 MiniSTR Loci for Improved Analysis of Degraded DNA Samples. J. Forensic Sci., 53(1): 1556-4029

Iranpur M. L., and Esmailizadeh A. K. (2014). Rapid Extraction of High Quality DNA from Whole Blood Stored at $4^{\circ} \mathrm{C}$ for Long Period. J. Biol. Med., www.protocolonline.com.

Lorenz, T. C. (2012). Polymerase chain reaction: Basic protocol plus troubleshooting and optimization strategies. J. Vis. Exp. 63(10): 3991-3998

Opel K., Chung D., Drabek J., Tatarek N., Jantz L., and McCord B. (2006). The Application of Miniplex Primer Sets in the Analysis of Degraded DNA from Human Skeletal Remains. J. Forensic Sci., 51: 351-35623.

Schoske, R., Vallone, P., Ruitberg, C., and Butler, J. (2003). Multiplex PCR design strategy used for the simultaneous amplification of $10 \mathrm{Y}$ chromosome short tandem repeat (STR) loci. Anal. Bioanal. Chem., 375: 333-342.

White, W., and Kusukawa, N. (1997). Agarose-Based System for Separation of Short Tandem Repeat Loci. BioTechniques, 22:976-980. 